\title{
Analysis on volatile components of co-fermented fruit wines by Lycium ruthenicum murray and wine grapes
}

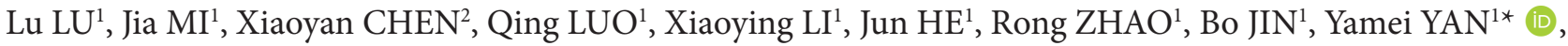 \\ Youlong $\mathrm{CAO}^{1}$
}

\begin{abstract}
The aim of this study was to detect the volatile components in co-fermented fruit wines made by Lycium ruthenicum Murray (LRM) and wine grapes using gas chromatography-mass spectrometry (GC-MS). A total of 52 kinds of volatile components were detected in the co-fermented fruit wines, more than those detected in commercially available Changyu dry red wine (30 kinds) and $0 \#$ wine (26 kinds) made by wine grapes in the laboratory. Esters (22 kinds) and alcohols (17 kinds) constituted a major proportion of co-fermented fruit wines, then followed by volatile acids, phenols, aldehydes and ketones. The relative intensity of aroma in the co-fermented fruit wines was greater than that of the Changyu wine and 0\# wine, exhibiting a comprehensive fruit and floral aroma profile. Additionally, grape wines (containing Changyu wine and 0\# wine) were distinguished from the co-fermented fruit wines (1\#-9\#), $1 \#$ wines distinguished from the other co-fermented fruit wines $(2 \#-8 \#)$ in second layer of clustering, indicating that the composition of raw material and fermentation conditions were the main influencing factor in the attributes of volatile components. Overall, co-fermented fruit wines possess more advantages in composition of volatile components and aromas, which showed a richer volatile and aroma structures.
\end{abstract}

Keywords: Lycium ruthenicum Murray; wine; GC-MS; volatile components; aromas.

Practical Application: Lycium ruthenicum Murray food process field.

\section{Introduction}

Lycium ruthenicum Murray (LRM) is a genus of Solanaceae, which is mainly distributed in the northwest of China, such as Loess Plateau, Ningxia, Gansu, Qinghai, Inner Mongolia, Xinjiang, and Tibet. In addition, it also grows in Central Asia, the Caucasus, and Europe (Yan et al., 2014; Wang et al., 2018). LRM fruits with purple-black berry color, and rich in polyphenolic compounds, especially anthocyanins (about $200 \sim 380 \mathrm{mg} / 100 \mathrm{~g}$ fresh weight), much higher than other colored fruits and vegetables (Zhang et al., 2018a; Yahui et al., 2016). Numerous studies have demonstrated that LRM plays a vital role in anti-oxidation (Wu et al., 2016), decreasing the levels of blood lipid (Tang et al., 2017), regulating the intestinal flora (Yan et al., 2018), inhibiting the cellular oxidative damage (Peng et al., 2019).

Although LRM is known to possess superior biological activity, maintaining the stability of anthocyanins can be an extremely difficult task owing to its degradation by various factors such as $\mathrm{pH}$, temperature, oxygen concentration, light and acylation degree (Sui et al., 2016; Xu et al., 2018), which greatly limits its development and utilization. The technology of fermentation is a very different process from thermal processes in the field of food processing. The acidic conditions and micro-oxygen environment are more suitable for the preservation of anthocyanins during the fermentation and aging period (Nie et al., 2017; HerasRoger et al., 2016). In addition, fermentation produces a large amount of esters, alcohols, fatty acids, and other substances by the metabolism of Saccharomyces cerevisiae and lactobacillus, which enhance the flavors of fruit wine (Styger et al., 2011).

Volatile and aroma components are the vital indicators for the evaluation of alcoholic products. In recent years, gas chromatography-mass spectrometry (GC-MS) has demonstrated successful applications in the analysis of fruit wines (Lee et al., 2018; Kang et al., 2016; Villano et al., 2017). The origin and variety of grapes (Cheng et al., 2015), fermentation process (Albanese et al., 2012; Wang et al., 2016), oak barrels, and aging time (Liu et al., 2016) are potential influencing factors that are utilized in determine the distinct composition of volatile components in the wine. Some scholars employed the GC-MS method for the determination of the volatile components in the red wines from France, Italy, Spain, and Poland, and 13 kinds of alcohols, 9 kinds of acids, 7 kinds of esters, 3 kinds of aldehydes, 2 kinds of ketones and a volatile phenol were identified. In fact, the results showed a considerable difference in the components of diethyl succinate, 4-ethyl phenol, phenylethyl alcohol, and benzyl alcohol in the wines of the abovementioned four countries (Stój et al., 2017). A study has shown that 2-hydroxy-propanoic acid ethyl ester, butanedioic acid monomethyl ester, 4-oxopentanoic acid ethyl ester, 1-dodecene, and 1,2,3-trimethoxy- 
5-methyl-benzene were quite different in contents between the red and white wines (Zhang \& Guo, 2017).

However, there is no study has researched or determined about the volatile and aroma components of LRM fermentation or co-fermented products. The purpose of this study is to determine the volatile components of the co-fermented fruit wines by LRM and wine grapes using GC-MS, meanwhile compared with the commercially available Changyu dry red wine and 0\# wine made by wine grapes in the laboratory, also analyzed the aroma profile of these wines. The results of this study will enrich the information of the volatile composition of the LRM and its fermentation products as this vital information will provide a theoretical basis for the comprehensive utilization of LRM.

\section{Materials and methods}

\subsection{Materials}

The fresh fruits of LRM and wine grapes (Cabernet Sauvignon, C.S) were collected from the National Gouji-Grape Germplasm Resources (Yinchuan, Ningxia, China); whereas the samples of 0 \# wine (made by C.S) and co-fermented fruit wines (made by LRM and C.S, numbered from 1\# to 9\#) were prepared in the laboratory. Furthermore, the commercially available Changyu dry red wine (made by C.S) was purchased from the Huarun supermarket (Yinchuan, China).

\subsection{Chemicals}

EX-V pectin impregnase, FX-10 active dry yeast, active lactic acid bacteria (Lactoenos 450 Pre AC) were all food grade and purchased from Laffort company (France), whereas 2-chlorophenylalanine as an internal standard was obtained from Sigma (St, Louis, MO, USA). The other measure reagents were chromatographically pure and purchased from Thermo Fisher Scientific (USA).

\subsection{Preparation of co-fermented fruit wines}

Fresh LRM and wine grapes mixed, then destemmed and crushed. Afterwards, these samples transferred into a stainless-steel tank, and a certain amount of the EX-V pectin impregnase was added. This solution was treated with sulfur dioxide $(30 \mathrm{mg} / \mathrm{L})$ and $18{ }^{\circ} \mathrm{C}$ cold maceration for a week. Then, FX-10 active dry yeast was added into the mixed juice for inoculation after the process of activation. The samples were stirred well and then fermented with $22 \pm 2{ }^{\circ} \mathrm{C}$ for eight to ten days until the value of residual sugar was less than $5 \mathrm{~g} / \mathrm{L}$. After alcoholic fermentation, the removed skins and seeds were mixed with free run wine and press wine into a new tank. Thereafter, the inoculated Lactoenos 450 Pre AC lactic acid bacteria by the process of activation was added to start the process of malic acid-lactic acid fermentation, with the condition $20 \pm 2{ }^{\circ} \mathrm{C}$ for one to two months, until the malic acid content with a small amount in the wine, transit into another tank, clarification for one month, and sulphiting of the wine $(40 \mathrm{mg} / \mathrm{L}$ of potassium metabisulfite), kept 5 months hermetically, become the new wine for experiment. 0 \# wine only made by wine grapes (C.S), prepared with the same brewing process of co-fermented fruit wines in the laboratory.
In this experiment, three factors were used to optimize the alcohol fermentation process by the orthogonal design (as shown in Table 1). In total, nine groups of co-fermented fruit wine samples were prepared with the same brewing process, and numbered from $1 \#$ to $9 \#$, respectively.

\subsection{GC-MS Analysis of volatile components}

The volatile components of wines were extracted by using headspace-solid-phase microextraction (HS-SPME) (Laaks et al., 2012). In total, weighed $1.0 \mathrm{~g}$ of $\mathrm{NaCl}$ into $10 \mathrm{~mL}$ of the wine samples, transferred into a $20 \mathrm{~mL}$ headspace bottle, each bottle pre-heated at $60^{\circ} \mathrm{C}$ for $5 \mathrm{~min}$. The SPME fiber (DVB/CAR/PDMS) was used to extract the volatile components from the headspace after stirring for $30 \mathrm{~min}$ at $60{ }^{\circ} \mathrm{C}$.

The volatile compounds of wine were identified and relatively quantified by Agilent Gasoline System (GC-7980A, MS-5975C, USA). The volatile compounds were desorbed in the splitless mode into a GC injection port that was equipped with Agilent HP-INNOWax column $(30 \mathrm{~m} \times 0.25 \mathrm{~mm} \times 0.25 \mu \mathrm{m}$, USA), Helium was used as the carrier gas at a linear velocity of $1.0 \mathrm{~mL} / \mathrm{min}$, kept the injector temperature at $250^{\circ} \mathrm{C}$ and the detector at $280^{\circ} \mathrm{C}$. Oven temperature was programmed from $40{ }^{\circ} \mathrm{C}(1 \mathrm{~min})$, increasing at $5^{\circ} \mathrm{C} / \mathrm{min}$ to $280^{\circ} \mathrm{C}$. Mass spectra was recorded in electron impact (EI) ionization mode at $70 \mathrm{eV}$, quadrupole mass detector at $150{ }^{\circ} \mathrm{C}$, and ion source and transfer line temperatures were set, respectively, at 230 and $280{ }^{\circ} \mathrm{C}$. Mass spectra was scanned in the range $\mathrm{m} / \mathrm{z}$ 30-400 AMU/s.

\subsection{Statistical analysis}

Identification of volatile compounds was achieved by comparing the mass spectra with the data system library (NIST2.0, US Department of commerce, Gaithersburg, MD, USA) and linear retention index, the collected mass spectra accurately identifies the volatile components in the samples. The peak area normalization method of the total volatile matter was used to calculate the relative content of various components. Principal component analysis (PCA) and clustering analysis were applied for the evaluation of the data of volatile components by SPSS21.0 software (SPSS Inc., USA) and Origin 2019b(OriginLab, USA).

Table 1. Factors and levels of orthogonal test designs.

\begin{tabular}{cccc}
\hline Number & $\begin{array}{c}\text { adding rate of } \\
\text { LRM and C.S } \\
(\mathrm{W} / \mathrm{W})\end{array}$ & $\begin{array}{c}\text { pectin compound } \\
\text { enzyme addition } \\
(\mathrm{g} / \mathrm{L})\end{array}$ & $\begin{array}{c}\text { Saccharomuces } \\
\text { cerevisiae addition } \\
(\mathrm{g} / \mathrm{L})\end{array}$ \\
\hline $1 \#$ & $1: 3$ & 0.03 & 0.15 \\
$2 \#$ & $1: 3$ & 0.05 & 0.20 \\
$3 \#$ & $1: 3$ & 0.07 & 0.25 \\
$4 \#$ & $1: 4$ & 0.03 & 0.20 \\
$5 \#$ & $1: 4$ & 0.05 & 0.25 \\
$6 \#$ & $1: 4$ & 0.07 & 0.15 \\
$7 \#$ & $1: 5$ & 0.03 & 0.25 \\
$8 \#$ & $1: 5$ & 0.05 & 0.15 \\
$9 \#$ & $1: 5$ & 0.07 & 0.20 \\
\hline
\end{tabular}


Table 2. Statistics of volatile components of different wines.

\begin{tabular}{|c|c|c|c|c|c|c|}
\hline \multirow{3}{*}{ Components } & \multicolumn{4}{|c|}{ Pure grape wines } & \multirow{2}{*}{\multicolumn{2}{|c|}{$\begin{array}{c}\text { Co-fermented fruit wines } \\
1 \#-9 \#\end{array}$}} \\
\hline & \multicolumn{2}{|c|}{ Changyu } & \multicolumn{2}{|c|}{ 0\# } & & \\
\hline & Varieties & $\mathrm{RC}(\%)$ & Varieties & $\mathrm{RC}(\%)$ & Varieties & $\mathrm{RC}(\%)$ \\
\hline Esters & 11 & 4.966 & 9 & 2.276 & 22 & $3.029 \sim 4.648$ \\
\hline Alcohols & 12 & 20.416 & 9 & 19.577 & 17 & $13.477 \sim 21.947$ \\
\hline Acids & 3 & 0.796 & 3 & 0.502 & 3 & $0.648 \sim 0.849$ \\
\hline Phenols & 2 & 0.328 & 1 & 0.049 & 3 & $0.104 \sim 0.679$ \\
\hline Aldehydes & 2 & 0.069 & 2 & 0.055 & 3 & $0.024 \sim 0.181$ \\
\hline Ketones & - & - & 2 & 0.276 & 3 & $0.239 \sim 0.532$ \\
\hline Amides & - & - & - & - & 1 & 0.013 \\
\hline
\end{tabular}

Note: RC is Relative content.

\section{Results and discussion}

\subsection{Volatile composition analysis}

The flavor and aroma of the wine were present due to the interactions between various large compounds, which are primarily perceived by the volatile state. In total, 52 kinds of volatile components were detected in the co-fermented fruit wines, which were much higher than the Changyu wine ( 30 kinds) and 0 \# wine (26 kinds) as shown in Table 2. The major volatile components were alcohols, esters, acids, volatile phenols, and aldehydes. Higher esters and alcohols were present in both types of wines. However, the varieties of esters and alcohols in the co-fermented wines were much higher than that of the Changyu wine and 0\# wine, which made the co-fermented fruit wines have a more complex volatile structure. The results of the volatile components and relative contents in different wines were presented in Table 3.

\subsection{Easters}

The esters was one of more vital factor for judging the aroma structure of wine that were intermediate metabolites mainly formed by the reaction of fatty acids by acetyl-coenzyme A, such as ethyl acetate, ethyl hexanoate, ethyl caprylate, and so on (Morales et al., 2017), usually closely related with the yeast strains, fermentation temperature, oxygen concentration, and other factors. As shown in Table 3, the common esters were isoamyl acetate, ethyl hexanoate, ethyl palmitate, ethyl caprylate, ethyl caprate, ethyl nonanoate, ethyl benzoate, ethyl laurate, ethyl 3-phenylpropionate, ethyl tetradecanoate, ethyl hexadec-9-enoate, especially, ethyl tetradecanoate and ethyl hexadec-9-enoate were characteristic volatile components, which showing a typical black berry fruit sweetness, violet perfume and fermentation aroma (Styger et al., 2011).

Among the nine groups of co-fermented fruit wines, the relatively high content of esters were ethyl caprylate, ethyl hexanoate, ethyl caprate, ethyl laurate, ethyl nonanoate, etc. These components showed a pleasant aroma of flowers and fruits, such as pineapple, apple, strawberry, rose flowers, formed a complex aroma system, which played a vital role in enriching the aroma structure of the wine body and increasing the aroma levels of the wines. The highest content of esters was ethyl caprylate (about $0.423 \sim 1.456 \%$ ), exhibiting a typical fruit aroma and brandy aroma, then followed by ethyl hexanoate $(0.432 \sim 0.834 \%)$, which give more strawberry and apple aromas.
The Changyu wine contains 11 kinds of esters, which were mainly ethyl acetate, ethyl butyrate, ethyl 2-methylbutyrate, ethyl 3-methylbutyrate, isoamyl acetate, ethyl hexanoate, diethyl succinate, diethyl glutarate, methyl salicylate, ethyl 2-phenylacetate, and ethyl palmitate. Among them, ethyl acetate and diethyl succinate were the obvious aroma characteristics components in the red wine (Lou et al., 2016; Silvia et al., 2004), the relative content of which were $1.944 \%$ and $2.000 \%$, respectively, with the grape and green fruity aroma. However, the proportions were too high and lead to aroma structure and composition were not rich enough. While $0 \#$ wine contains less esters in both variety (9 kinds) and relative content (2.276\%), but ethyl acetate and diethyl succinate were main esters composition, which similar to Changyu wine.

\subsection{Alcohols}

Alcohols were secondary metabolites, which were mostly formed by alcohol fermentation of Saccharomyces cerevisiae through glucose assimilation or dehydroxylation and dehydrogenation of amino acids (such as leucine, isoleucine, phenylalanine, etc.) (Silvia et al., 2004; Lee et al., 2019), or degradation of biological macromolecular substances, (such as purines, pyrimidines) (Çelebi Uzkuç et al., 2020), which were important volatile components in the alcohol products.

There were 17 kinds of alcohols in the 9 groups of co-fermented fruit wines, the main higher representative alcohols were isobutanol, isoamyl alcohol, phenylethyl alcohol, propanol, and so on, which showed fresh floral aroma, and the relative content was quite different in each group from 13.477 to $21.947 \%$. In addition, the co-fermented fruit wines contain three kinds of terpene alcohol, (2E, 6E)-farnesol, geraniol and citronellol. These components were secondary metabolites formed by the synthesis of acetyl-coenzyme A (Morales et al., 2017; Silvia et al., 2004; Çelebi Uzkuç et al., 2020), commonly exist with free and glycosidic patterns in the fruit and peel, also not changed by the metabolism of yeast, exhibiting a pleasant lemon fragrance and rose scent. However, these alcohols were not detected in Changyu wine and $0 \#$ wine.

In the Changyu wine, 12 kinds of alcohols were detected, while $0 \#$ wine contains 9 kinds correspondingly, the relative 
Table 3. Volatile components and relative content of different wines.

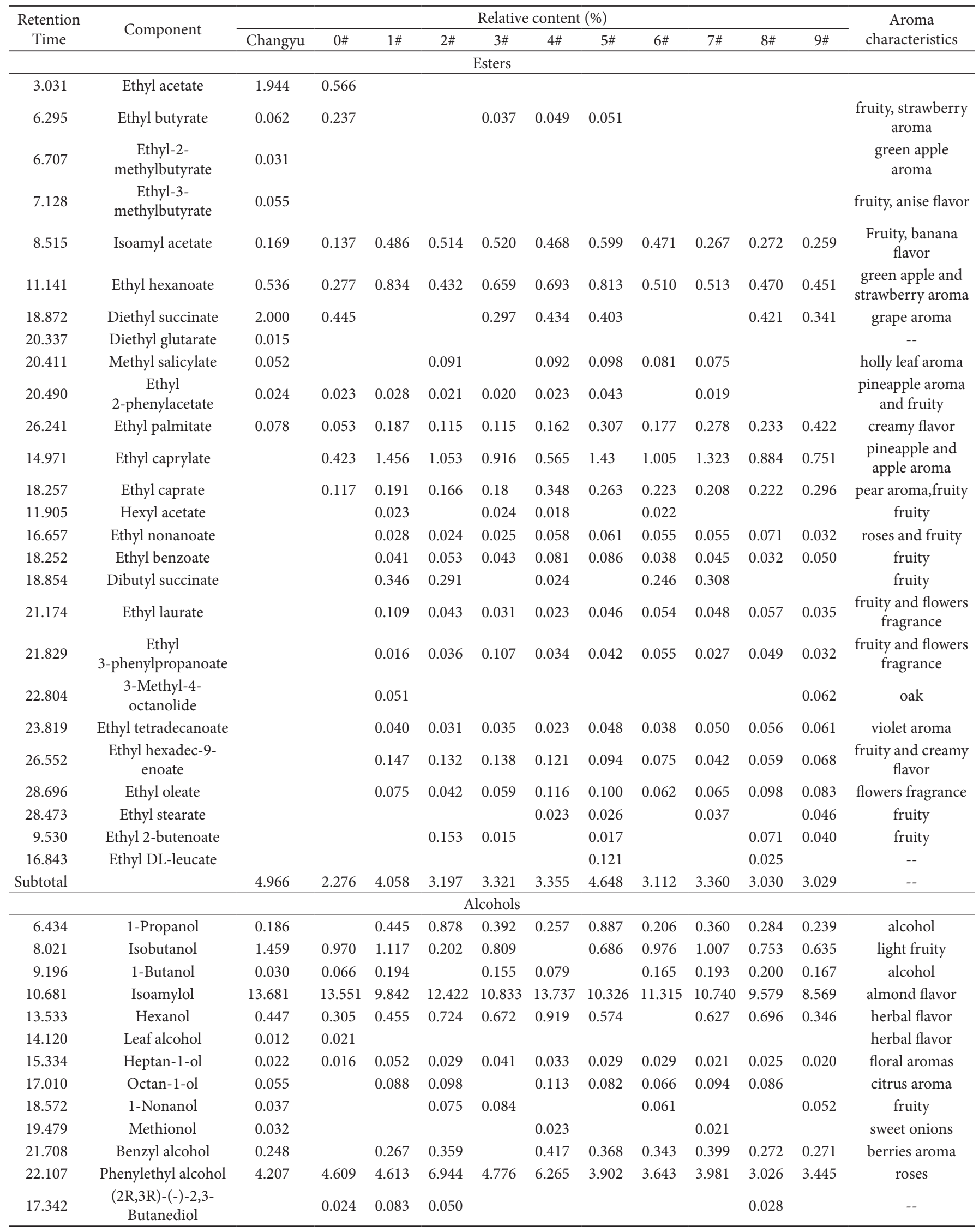


Original Article

Lu et al.

Table 3. Continued...

\begin{tabular}{|c|c|c|c|c|c|c|c|c|c|c|c|c|c|}
\hline \multirow{2}{*}{$\begin{array}{l}\text { Retention } \\
\text { Time }\end{array}$} & \multirow{2}{*}{ Component } & \multicolumn{11}{|c|}{ Relative content (\%) } & \multirow{2}{*}{$\begin{array}{c}\text { Aroma } \\
\text { characteristics }\end{array}$} \\
\hline & & Changyu & $0 \#$ & $1 \#$ & $2 \#$ & $3 \#$ & $4 \#$ & $5 \#$ & $6 \#$ & $7 \#$ & $8 \#$ & 9\# & \\
\hline 12.703 & 2-Ethyl-1-butanol & & 0.013 & 0.031 & 0.035 & 0.017 & 0.043 & 0.098 & 0.609 & 0.058 & 0.027 & & mushroom aroma \\
\hline 17.368 & $( \pm)$-2,3-Butanediol & & & 0.054 & & & 0.040 & & & 0.061 & & & -- \\
\hline 20.099 & Citronellol & & & 0.040 & 0.050 & 0.041 & & 0.050 & 0.020 & 0.073 & & & $\begin{array}{c}\text { lemon and roses } \\
\text { aroma }\end{array}$ \\
\hline 21.222 & Geraniol & & & & & 0.031 & & & & 0.028 & & & roses \\
\hline 27.361 & $(2 \mathrm{E}, 6 \mathrm{E})-$ Farnesol & & & & & & 0.021 & & & 0.020 & & & $\begin{array}{c}\text { lemon, roses and } \\
\text { honey aroma }\end{array}$ \\
\hline Subtotal & & 20.416 & 19.577 & 17.280 & 21.866 & 17.851 & 21.947 & 17.002 & 17.433 & 17.683 & 14.976 & 13.744 & \\
\hline \multicolumn{14}{|c|}{ Volatile acids } \\
\hline 21.807 & 1-Hexanoic acid & 0.058 & 0.078 & & & & & & & & & & -- \\
\hline 24.391 & Octanoic acid & 0.437 & 0.365 & 0.464 & 0.487 & 0.849 & 0.783 & 0.605 & 0.648 & 0.635 & 0.710 & 0.583 & cheese aroma \\
\hline 16.080 & Acetic acid & 0.201 & 0.059 & 0.319 & 0.240 & & & 0.134 & & 0.050 & & & tart flavor \\
\hline 22.995 & 2-Ethylcaproic acid & & & 0.016 & 0.023 & & & 0.039 & & 0.025 & & 0.078 & fat flavor \\
\hline Subtotal & & 0.796 & 0.502 & 0.799 & 0.749 & 0.849 & 0.783 & 0.777 & 0.648 & 0.710 & 0.710 & 0.662 & \\
\hline \multicolumn{14}{|c|}{ Volatile phenols } \\
\hline 25.466 & 4-Ethylphenol & 0.016 & & 0.480 & 0.471 & 0.216 & 0.064 & 0.041 & 0.500 & 0.242 & 0.389 & 0.217 & -- \\
\hline 26.936 & 2,4-Di-t-butylphenol & 0.312 & 0.049 & 0.020 & & 0.061 & 0.075 & 0.063 & 0.043 & & & 0.108 & -- \\
\hline 26.936 & $\begin{array}{l}\text { 2,5-Di-tert- } \\
\text { butylphenol }\end{array}$ & & & 0.051 & 0.059 & & & & & 0.148 & 0.070 & & smoky flavor \\
\hline Subtotal & & 0.328 & 0.049 & 0.550 & 0.531 & 0.277 & 0.139 & 0.104 & 0.543 & 0.390 & 0.679 & 0.648 & \\
\hline \multicolumn{14}{|c|}{ Aldehydes } \\
\hline 14.291 & Nonanal & 0.044 & 0.024 & & 0.034 & & & 0.057 & & 0.036 & 0.039 & 0.040 & $\begin{array}{l}\text { roses and plum } \\
\text { aroma }\end{array}$ \\
\hline 15.598 & Furfural & 0.025 & & & & 0.023 & & & 0.023 & & & & floral aromas \\
\hline 16.583 & Benzaldehyde & & 0.031 & 0.024 & 0.125 & 0.019 & 0.014 & 0.124 & 0.047 & 0.063 & 0.039 & 0.069 & almond flavor \\
\hline Subtotal & & 0.069 & 0.055 & 0.024 & 0.159 & 0.042 & 0.014 & 0.181 & 0.070 & 0.099 & 0.078 & 0.110 & \\
\hline \multicolumn{14}{|c|}{ Ketones } \\
\hline 12.322 & Acetoin & & 0.261 & & 0.425 & 0.258 & 0.180 & 0.219 & 0.370 & 0.217 & 0.508 & 0.224 & Sweet milk aroma \\
\hline 20.971 & $\beta$-Damascenone & & 0.015 & & 0.067 & 0.026 & 0.033 & 0.020 & 0.031 & 0.028 & 0.024 & 0.023 & roses \\
\hline 22.809 & $\begin{array}{l}\text { (4R,5R)-5-Butyl-4- } \\
\text { methyloxolan-2-one }\end{array}$ & & & & & & 0.041 & & 0.042 & 0.038 & & & herbal flavor \\
\hline Subtotal & & 0 & 0.276 & 0 & 0.493 & 0.284 & 0.254 & 0.239 & 0.443 & 0.282 & 0.532 & 0.247 & \\
\hline \multicolumn{14}{|c|}{ Amides } \\
\hline 21.397 & $\begin{array}{l}\text { n-(3-Methylbutyl) } \\
\text { acetamide }\end{array}$ & & & 0.013 & & & & & & & & & tobacco flavor \\
\hline Subtotal & & 0 & 0 & 0.013 & 0 & 0 & 0 & 0 & 0 & 0 & 0 & 0 & \\
\hline
\end{tabular}

content were $20.416 \%$ and $19.577 \%$ respectively, and had higher content of isoamylol similarly.

\subsection{Volatile acids}

Volatile acids play a crucial role in the well-balanced alcohol and astringent on the palate. Most of it comes from the fermentation of by-products through higher fatty acid catabolism or alcohols and aldehydes oxidation, which was marginally derived from the degradation of amino acids (Styger et al., 2011).

The co-fermented fruit wines consist of octanoic acid, acetic acid and 2-ethylcaproic acid; whereas Changyu wine and 0\# wine consist of 1-hexanoic acid, octanoic acid, and acetic acid. The 1-hexanoic acid has a cheese and fatty flavor, and octanoic acid showing a variety of flavors such as fruit, peach, strawberry, and pineapple. These acids could maintain the balance of the wine, and also provide a refreshing taste (threshold $500 \mu \mathrm{g} / \mathrm{L}$ ) (Morales et al., 2017).

\subsection{Volatile phenols}

Three kinds of volatile phenols were detected by GC-MS, there were 2,5-di-tert-butylphenol, 4-ethylphenol and 2,4-ditert-butylphenol, especially, the 4-ethylphenol and 2,4-di-tertbutylphenol were mainly produced by the wild yeast (Silvia et al., 2004; Lee et al., 2019; Zhang et al., 2018b), and detected in both co-fermented fruit wines and Changyu wine. However, with the concentration increasing $(>650 \mu \mathrm{g} / \mathrm{L})$, the flavor changed to the fishy smell, affecting the wine body taste and flavor seriously. Yeast metabolite with anthocyanins could produce pyran-type anthocyanins during the fermentation period, which would inhibit the formation of ethylphenol during the aging period (Pons et al., 2017).

\subsection{Aldehydes}

The Changyu wine consists of two kinds of aldehydes, nonanal and furfural, with a total relative content of $0.069 \%$, whereas the co-fermented fruit wines consist of one or two of nonanal, furfural, 
and benzaldehyde, and the relative content of aldehydes was $0.014 \sim 0.159 \%$. Nonanal has a rose aroma, furfural has an incense and floral aroma, and usually exist in new wines or grape juice (Yahui et al., 2016; Benito et al., 2009). Benzaldehyde has an almond flavor, with a glycoside form in the nuts, makes a great contribution to Cabernet Sauvignon wine flavor (Çelebi Uzkuç et al., 2020), it was also detected in LRM and other berry fruits in a many work of literatures (Styger et al., 2011; Benito et al., 2009; Zhang et al., 2019).

\subsection{Ketones}

Ketones were typically produced by the malic acid-lactic acid fermentation (Yahui et al., 2016). The Changyu wine doesn't consist of any ketones, $0 \#$ wine contains acetoin and $\beta$-damascenone, whereas the co-fermented fruit wines consist of $\beta$-damascenone, (4R, 5R)-5butyl-4-methyloxolan-2-one and acetoin. $\beta$-Damascenone had a special aroma in grapes and some berries, formed by oxidation of isoprene compounds through carotenoids in C9-C10 / C9'-C10' double bond position degradation. It was the most typical aroma components in the grapes or red wines, showing tropical fruit aromas and scent flavor, however, the threshold was very low in the aqueous solution.

\subsection{Aroma analysis}

Volatile components being responsible for aromas, and different volatile components may exhibit the same or different aroma characteristics. According to Table 3, aromas were defined as seven main types according to the volatile components (Sun et al., 2018), aroma profiles were presented in Figure 1. The aroma intensity of co-fermented fruit wines was fruit flavor $>$ floral flavor $>$ plants flavor $>$ balsam flavor $>$ chemical flavor $>$ greasy flavor $>$ smoky flavor, which showing a pleasant fruit and floral aromas. The aroma types of the three types of wines both exhibit a similar characteristic in fruit aromas, but co-fermented fruit wines were greater than that of the Changyu wine and 0\# wine. In addition, there were fewer smoky aromas in the three types of wines, which were closely related to the oak barrels and aging time (Wedler et al., 2015).

\subsection{Principal component analysis}

The PCA was performed to characterize the evolution of attributes of volatile components in wines. The cumulative contribution rate of the first five components has closer to $75 \%$

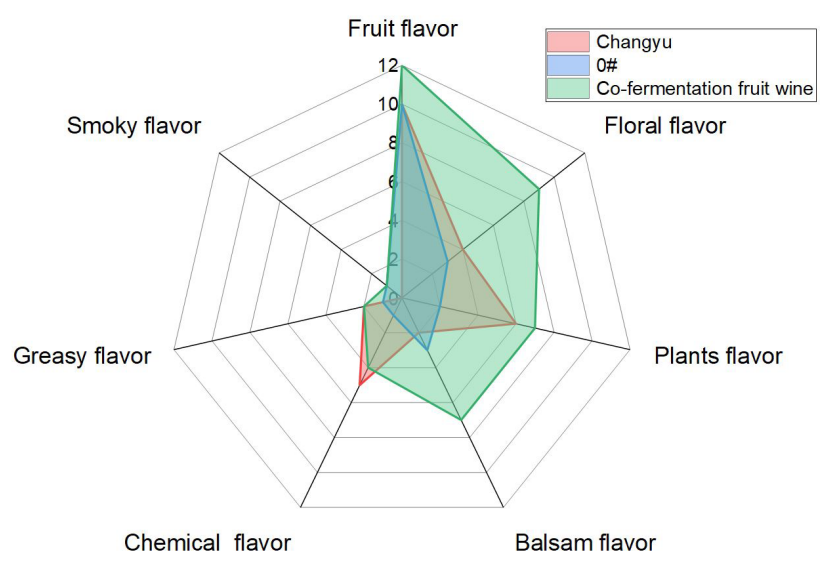

Figure 1. Aroma profiles of different wines. in Figure 2a, so it can be determined that these five components were the main components in the Changyu wine, $0 \#$ wine and the co-fermented fruit wines.

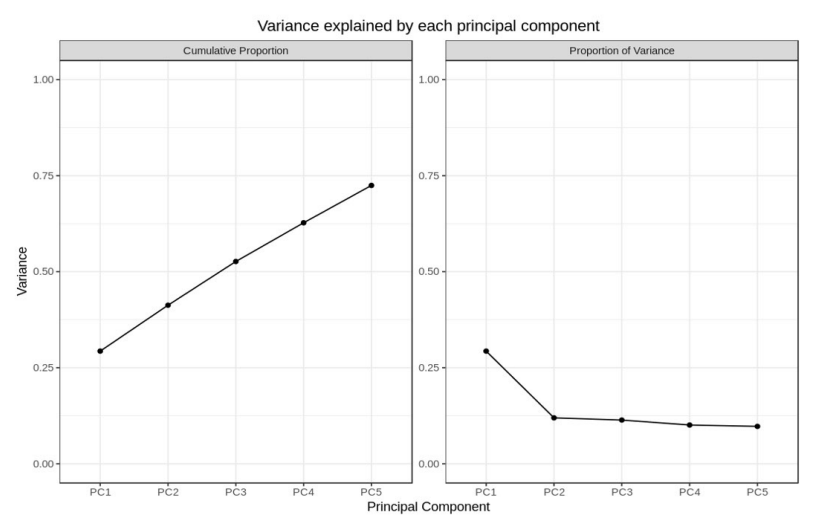

(a)

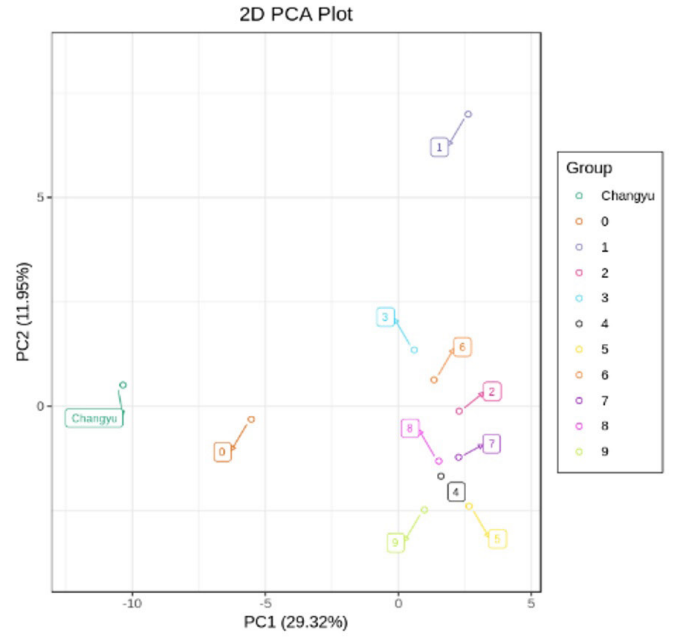

(b)

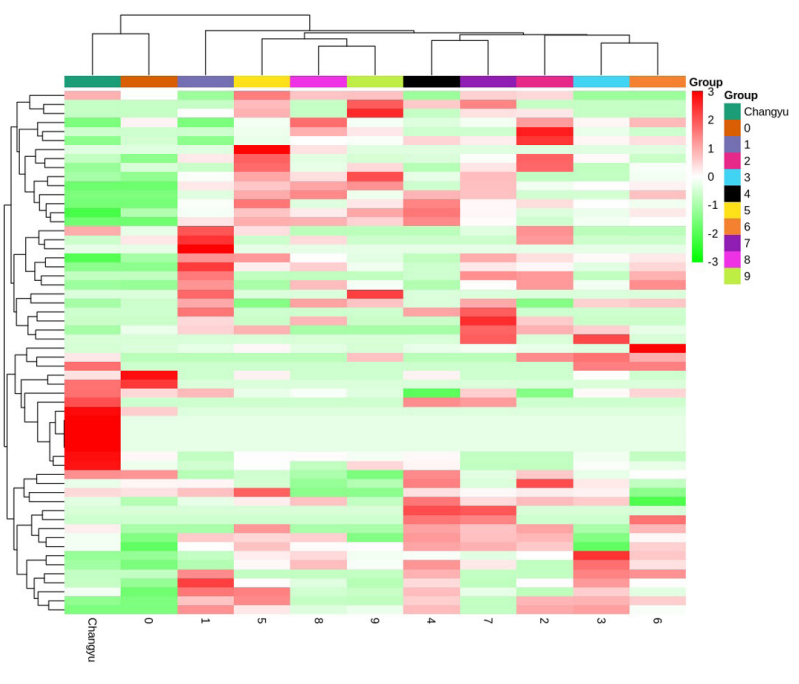

(c)

Figure 2. Principal component analysis of volatile components attributes (a), PCA plot (b) and heatmap (c) of different wines. 
The PCA plot of volatile components in Figure $2 \mathrm{~b}$ shows that Changyu wine and $0 \#$ wine were different from the co-fermented fruit wines (1\#-9\#) with respect to the PC1 dimension (explaining $29.32 \%$ of the variance), which indicated that raw material composition was the main influencing factor in the attributes of volatile components. Moreover, 1\# wines were different from other co-fermented fruit wines $(2 \#-8 \#)$ with respect to the PC2 dimension (explaining 11.95\% of the variance), which indicated that PC2 components could be mainly representative of differentiation of fermentation process, and lead to different compositions of volatile components in the co-fermented fruit wines. The cluster analysis was presented in Figure $2 c$. The wine samples were divided into two parts: grape wine (contained Changyu wine and $0 \#$ wine) and co-fermented fruit wines, which consistent with the PCA. Due to the orthogonal experiment design, the results involving interactions between multiple factors, such as pectinase adding amount, yeast adding amount, and the formation mechanism of volatile components in co-fermented fruit wines would be need explored deeply.

\section{Conclusions}

Volatile components are very important for alcohol products. In this study, the volatile components in the co-fermentation wine of LRM and wine grapes were determined and analyzed by the GC-MS, and 52 kinds of volatile components were detected, the variety and relative content were both higher than that of the Changyu (30 kids) wine and 0\# wine (26 kinds). Esters (22 kinds) and alcohols (17 kinds) constituted a major proportion of these co-fermented fruit wines, the relative contents of $30.29 \%$ and $13.477 \%$ (except ethanol), respectively, then followed by volatile acids, phenols, aldehydes and ketones. The analysis of aroma composition demonstrated that the relative intensity of each aroma flavor in the co-fermented fruit wines was greater than that of the Changyu wine and $0 \#$ wine, exhibiting a comprehensive fruit and floral aroma profile. The results of PCA showed the grape wines (contained Changyu wine and $0 \#$ wine) were distinguished from the co-fermented fruit wines (1\#-9\#), indicating that the raw material composition was the main influencing factor the attributes of volatile components. The $1 \#$ wine was separated from the other co-fermented fruit wines (2\#-8\#), which were affected by raw material composition and fermentation technological conditions, including addition ratio of LRM and wine grapes, addition of yeast and pectin compound enzyme, have interactions on aromas. Fermentation-derived volatile compounds are the largest percentage of the total aroma composition of wine, mainly including formation of many alcohols and esters by Saccharomyces cerevisiae, establishes the basic aroma structure of the wine. Actually, malic acid-lactic acid fermentation is also an important period for the formation of volatile components, which could modify the aromatic properties of wines by releasing notable concentrations of diacetyl (2,3-butanedione) and other carbonyl compounds obtained from citric acid, which contribute to the buttery or aroma of wines (Belda et al., 2017). Overall, the co-fermented fruit wines may possess more advantages in the composition of volatile components and aromas, and showing a richer volatile and aroma structures. However, it's not clear yet whether there is a significantly difference in volatile composition between co-fermentation and single fermentation of LRM, and the influence on the stability of phenolic compounds and anthocyanins of co-fermentation is unknown, which needs further exploration.

\section{References}

Albanese, D., Attanasio, G., Cinquanta, L., \& Di Matteo, M. (2012). Volatile compounds in red wines processed on an industrial scale by short pre-fermentative cold maceration. Food and Bioprocess Technology, 6(11), 3266-3272. http://dx.doi.org/10.1007/s11947012-0798-5.

Belda, I., Ruiz, J., Esteban-Fernández, A., Navascués, E., Marquina, D., Santos, A., \& Moreno-Arribas, M. V.. (2017). Microbial contribution to wine aroma and its intended use for wine quality improvement. Molecules (Basel, Switzerland), 22(2), 189. http://dx.doi.org/10.3390/ molecules22020189. PMid:28125039.

Benito, S., Palomero, F., Morata, A., Uthurry, C., \& Suárez-Lepe, J. A. (2009). Minimization of ethylphenol precursors in red wines via the formation of pyranoanthocyanins by selected yeasts. International Journal of Food Microbiology, 132(2-3), 145-152. http://dx.doi. org/10.1016/j.ijfoodmicro.2009.04.015. PMid:19439384.

Çelebi Uzkuç, N. M., Şişli, B., Ay, M., Togay, S. Ö., Karagül Yüceer, Y., Bayhan, A., \& Kirca Toklucu, A. (2020). Effects of spontaneous fermentation on karalahna and cabernet sauvignon young red wines: volatile compounds, sensory profiles and identification of autochthonous yeasts. European Food Research and Technology, 246(1), 81-92. http://dx.doi.org/10.1007/s00217-019-03395-w.

Cheng, G., Liu, Y., Yue, T. X., \& Zhang, Z. W. (2015). Comparison between aroma compounds in wines from four vitis vinifera grape varieties grown in different shoot positions. Food Science and Technology (Campinas), 2(2), 237-246. http://dx.doi.org/10.1590/1678-457X.6438.

Heras-Roger, J., Díaz-Romero, C., \& Darias-Martín, J. (2016). What gives a wine its strong red color? Main correlations affecting copigmentation. Journal of Agricultural and Food Chemistry, 64(34), 6567-6574. http:// dx.doi.org/10.1021/acs.jafc.6b02221. PMid:27523569.

Kang, H. R., Hwang, H. J., Lee, J. E., \& Kim, H. R. (2016). Quantitative analysis of volatile flavor components in Korean alcoholic beverage and Japanese sake using SPME-GC/MS. Food Science and Biotechnology, 25(4), 979-985. http://dx.doi.org/10.1007/s10068-016-0159-7. PMid:30263363.

Laaks, J., Letzel, T., Schmidt, T. C., \& Jochmann, M. A. (2012). Fingerprinting of red wine by headspace solid-phase dynamic extraction of volatile constituents. Analytical and Bioanalytical Chemistry, 403(8), 2429-2436. http://dx.doi.org/10.1007/s00216012-5909-7. PMid:22434273.

Lee, J. E., Yun, J. H., Lee, A. R., \& Kim, S. S. (2018). Volatile components and sensory properties of jujube wine as affected by material preprocessing. International Journal of Food Properties, 21(1), 20522061. http://dx.doi.org/10.1080/10942912.2018.1514506.

Lee, S. B., Banda, C., \& Park, H. D. (2019). Effect of inoculation strategy of non-Saccharomyces yeasts on fermentation characteristics and volatile higher alcohols and esters in campbell early wines. Australian Journal of Grape and Wine Research, 25(4), 384-395. http://dx.doi. org/10.1111/ajgw.12405.

Liu, D., Xing, R. R., Li, Z., Yang, D. M., \& Pan, Q. H. (2016). Evolution of volatile compounds, aroma attributes, and sensory perception in bottle-aged red wines and their correlation. European Food Research and Technology, 242(11), 1937-1948. http://dx.doi.org/10.1007/ s00217-016-2693-1.

Lou, S. T., Cheng, H., \& Lin, W. W. (2016). Analysis of volatile components of Lycium ruthenicum Murr. by SPME-GC/MS. Journal of Chinese 
Institute of Food Science and Technology, 16, 245-250. http://dx.doi. org/10.16429/j.1009-7848.2016.10.034.

Morales, M. L., Fierro-Risco, J., Callejón, R. M., \& Paneque, P. (2017). Monitoring volatile compounds production throughout fermentation by Saccharomyces and non-Saccharomyces strains using headspace sorptive extraction. Journal of Food Science and Technology, 54(2), 538557. http://dx.doi.org/10.1007/s13197-017-2499-6. PMid:28242953.

Nie, Q., Feng, L., Hu, J. L., Wang, S. N., Chen, H. H., Huang, X. J., Nie, S. P., Xiong, T., \& Xie, M. Y. (2017). Effect of fermentation and sterilization on anthocyanins in blueberry. Journal of the Science of Food and Agriculture, 97(5), 1459-1466. http://dx.doi.org/10.1002/ jsfa.7885. PMid:27384605.

Peng, Y., Yan, Y. M., Wan, P., Chen, D., Ding, Y., Ran, L. W., Mi, J., Lu, L., Zhang, Z. Z., Li, X. Y., Zeng, X. X., \& Cao, Y. L. (2019). Gut microbiota modulation and anti-inflammatory properties of anthocyanins from the fruits of Lycium ruthenicum Murray in dextran sodium sulfate-induced colitis in mice. Free Radical Biology \& Medicine, 136, 96-108. http://dx.doi.org/10.1016/j.freeradbiomed.2019.04.005. PMid:30959170.

Pons, A., Allamy, L., Lavigne, V., Dubourdieu, D., \& Darriet, P. (2017). Study of the contribution of massoia lactone to the aroma of merlot and cabernet sauvignon musts and wines. Food Chemistry, 232, 229236. http://dx.doi.org/10.1016/j.foodchem.2017.03.151.

Silvia, M.R., Fanny, R., Paula, C., Delgadillo, L., \& Manuel, A. C. (2004). Volatile composition of Baga red wine: assessment of the identification of the would-be impact odourants. Analytica Chimica Acta, 513(1), 257-262. http://dx.doi.org/10.1016/ j.aca.2003.10.009.

Stój, A., Czernecki, T., Domagala, D., \& Targonski, Z. (2017). Comparative characterization of volatile profiles of French, Italian, Spanish, and Polish red wines using headspace solid-phase microextraction/ gas chromatography-mass spectrometry. International Journal of Food Properties, 20, S830-S845. https://doi.org/10.1080/1094291 2.2017.1315590.

Styger, G., Prior, B., \& Bauer, F. F. (2011). Wine flavor and aroma. Journal of Industrial Microbiology \& Biotechnology, 38(9), 1145-1159. http:// dx.doi.org/10.1007/s10295-011-1018-4. PMid:21786136.

Sui, X., Bary, S., \& Zhou, W. B. (2016). Changes in the color, chemical stability and antioxidant capacity of thermally treated anthocyanin aqueous solution over storage. Food Chemistry, 192, 516-524. http:// dx.doi.org/10.1016/j.foodchem.2015.07.021. PMid:26304379.

Sun, W. X., Hu, K., Zhang, J. X., Zhu, X. L., \& Tao, Y. S. (2018). Aroma modulation of Cabernet Gernischt dry red wine by optimal enzyme treatment strategy in winemaking. Food Chemistry, 245, 1248-1256. http://dx.doi.org/10.1016/j.foodchem.2017.11.106. PMid:29287349.

Tang, J. L., Yan, Y. M., Ran, L. W., Mi, J., Sun, Y., Lu, L., Gao, Y. X., Zeng, X. X., \& Cao, Y. L. (2017). Isolation, antioxidant property and protective effect on PC12 cell of the main anthocyanin in fruit of Lycium ruthenicum Murray. Journal of Functional Foods, 30, 97-107. http://dx.doi.org/10.1016/j.jff.2017.01.015.

Villano, C., Lisanti, M. T., Gambuti, A., Vecchio, R., Moio, L., Frusciante, L., Aversano, R., \& Carputo, D. (2017). Wine varietal authentication based on phenolics, volatiles and DNA markers: State of the art, perspectives and drawbacks. Food Control, 80, 1-10. http://dx.doi. org/10.1016/j.foodcont.2017.04.020.

Wang, J., Huo, S. F., Zhang, Y. X., Liu, Y. P., \& Fan, W. X. (2016). Effect of different pre-fermentation treatments on polyphenols, color, and volatile compounds of three wine varieties. Food Science and
Biotechnology, 25(3), 735-743. http://dx.doi.org/10.1007/s10068016-0127-2. PMid:30263331.

Wang, Z. C., Yan, Y. Z., Nisar, T., Zou, L., Yang, X., Niu, P. F., Sun, L. J., \& Guo, Y. R. (2018). Comparison and multivariate statistical analysis of anthocyanin composition in Lycium ruthenicum Murray from different regions to trace geographical origins: the case of China. Food Chemistry, 246, 233-241. http://dx.doi.org/10.1016/j. foodchem.2017.11.030.

Wedler, H. B., Pemberton, R. P., \& Tantillo, D. J. (2015). Carbocations and the complex flavor and bouquet of wine: mechanistic aspects of terpene biosynthesis in wine grapes. Molecules (Basel, Switzerland), 20(6), 10781-10792. http://dx.doi.org/10.3390/molecules200610781. PMid:26111168.

Wu, T., Lv, H. Y., Wang, F. Z., \& Wang, Y. (2016). Characterization of polyphenols from Lycium ruthenicum fruit by UPLC-Q-TOF/MSE and their antioxidant activity in Caco-2 cells. Journal of Agricultural and Food Chemistry, 64(11), 2280-2288. http://dx.doi.org/10.1021/ acs.jafc.6b00035. PMid:26963650.

Xu, X. J., Fang, S., Li, Y. H., Zhang, F., Shao, Z. P., Zeng, Y. T., Chen, J., \& Meng, Y. C. (2018). Effects of low acyl and high acyl gellan gum on the thermal stability of purple sweet potato anthocyanins in the presence of ascorbic acid. Food Hydrocolloids, 86, 116-123. http:// dx.doi.org/10.1016/j.foodhyd.2018.03.007.

Yahui, L., Xiaobo, Z., Tingting, S., Jiyong, S., Jiewen, Z., \& Holmes, M. (2016). Determination of geographical origin and anthocyanin content of black goji berry (Lycium ruthenicum Murr.) using nearinfrared spectroscopy and chemometrics. Food Analytical Methods, 10, 1034-1044. http://dx.doi.org/10.1039/C5AY01404B.

Yan, Y. M., Dai, G. L., Ran, L. W., Luo, Q., Li, X. Y., Qin, K., Wu, P. J., Zeng, Y. X., \& Cao, Y. L. (2014). The polyphenols composition of Lycium ruthenicum Murray from different places. Zhongguo Nong Ye Ke Xue, 47, 4540-4550.

Yan, Y. M., Peng, Y. J., Tang, J. L., Mi, J., Lu, L., Li, X. Y., Ran, L. W., Zeng, Y. X., \& Cao, Y. L. (2018). Effects of anthocyanins from the fruit of Lycium ruthenicum Murray on intestinal microbiota. Journal of Functional Foods, 48, 533-541. http://dx.doi.org/10.1016/j. jff.2018.07.053.

Zhang, C.-Y., \& Guo, M.-Q. (2017). Analysis and differentiation of the volatile compounds in red and white wines using desiccated headspace gas chromatography-mass spectrometry coupled with chemometrics. Food Analytical Methods, 10(11), 3531-3537. http:// dx.doi.org/10.1007/s12161-017-0924-0.

Zhang, G., Chen, S. S., Zhou,W., Meng, J., Deng, K., Zhou, H. N., Hu, N., \& Suo, Y. R. (2018a). Rapid qualitative and quantitative analyses of eighteen phenolic compounds from Lycium ruthenicum Murray by UPLC-Q-Orbitrap MS and their antioxidant activity. Food Chemisry, 269, 150-156. http://dx.doi.org/10.1016/j.foodchem.2018.06.132.

Zhang, X. K., Lan, Y. B., Zhu, B. Q., Xiang, X. F., Duan, C. Q., \& Shi, Y. (2018b). Changes in monosaccharides, organic acids and amino acids during Cabernet Sauvignon wine ageing based on a simultaneous analysis using gas chromatography-mass spectrometry. Journal of the Science of Food and Agriculture, 98(1), 104-112. http://dx.doi. org/10.1002/jsfa.8444. PMid:28543285.

Zhang, X. Y., Kontoudakis, N., Blackman, J., Šuklje, K., Antalick, G., \& Clark, A. C. (2019). Determination of 13 volatile aldehyde compounds in wine by GC-QQQ-MS: p-benzoquinone to dissociate hydrogen sulfite addition products. Food Analytical Methods, 12(6), 1285-1297. http://dx.doi.org/10.1007/s12161-019-01463-1. 